\title{
Consistent condom use and its predictors among female sexual Partners of People who Inject Drugs in Klang Valley, Malaysia
}

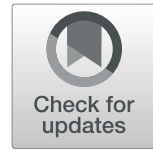

\author{
Rosliza Abdul Manaf ${ }^{1,2^{*}}$ (D) Nigel Dickson ${ }^{2}$, Sarah Lovell ${ }^{3}$ and Faisal Ibrahim ${ }^{1}$
}

\begin{abstract}
Background: Men who inject drugs (MWIDs) comprise the highest percentage of diagnosed HIV cases in Malaysia. Their female partners risk being infected through unprotected sexual contact. This paper reports the prevalence of consistent condom use and its predictors among the wives and regular sexual partners of MWIDs in Klang Valley, Malaysia.

Methods: A cross-sectional study using a self-administered questionnaire was conducted among the wives and regular sexual partners of MWIDs in the study location; 221 women were recruited through respondentdriven sampling. Data were analysed descriptively for the prevalence of consistent condom use, HIV status and HIV risk-related behaviour. Subsequently, simple and multiple logistic regressions were undertaken to identify the predictors of consistent condom use.

Results: The prevalence of consistent condom use among respondents was $19.5 \%$. Slightly more than half (52.5\%) of respondents had never used condoms with their partner. Fourteen women (6.3\%) reported being HIV positive. While $7.7 \%$ had HIV-positive partners, $45.7 \%$ were unaware of their partner's HIV status.

Consistent condom use was significantly higher among single women ( $\mathrm{AOR}=4.95 ; 95 \% \mathrm{Cl}: 2.45$, 9.99), women who lived in urban areas ( $A O R=2.97 ; 95 \% \mathrm{Cl}: 1.30,6.78)$, HIV-positive women ( $\mathrm{AOR}=3.45 ; 95 \% \mathrm{Cl}: 1.13,10.5)$ and women involved in sex work ( $\mathrm{AOR}=3.55,95 \% \mathrm{Cl}: 1.45,8.67)$.

Conclusions: Inconsistent condom use among the majority of female sexual partners of MWIDs underscores the heightened risk faced by these women and calls for alternative prevention methods that women are able to control.
\end{abstract}

Keywords: Condom use, Sexual partners, MWID, Malaysia, HIV risk

\section{Introduction}

Since the first case was reported in Malaysia in 1986, HIV has predominantly affected men, with the sharing of injecting equipment being the most common mode of transmission [1]. Over recent years, there has been concern over the increasing number of cases of heterosexual transmission of HIV in Malaysia, resulting in the changing gender distribution of the disease, which is currently increasing among women [2]. The percentage of

\footnotetext{
*Correspondence: rosliza_abmanaf@upm.edu.my; rosliza72@yahoo.co.uk 1 Department of Community Health Faculty of Medicine \& Health Sciences, Universiti Putra Malaysia, 43400 Serdang, Selangor, Malaysia

${ }^{2}$ Department of Preventive \& Social Medicine, Dunedin School of Medicine, University of Otago, P.O. Box 56, Dunedin 9054, New Zealand Full list of author information is available at the end of the article
}

HIV diagnosis among women has escalated from $5 \%$ in 1997 to $21 \%$ in 2017 [1]. Similar situations have been reported in several other Asian countries [3]. These women are at an increased risk of contracting HIV, mainly through unprotected sexual contact with their infected partners. The risk is also frequently augmented by power imbalances in sexual decision making, which are associated with lower rates of condom use among women than among men [4-6].

HIV prevalence among the Malaysian general population was reported as less than $1 \%$. However, the prevalence remains high among high-risk groups, such as female sex workers (6.3\%), men who have sex with men (21.6\%), transgender women $(10.9 \%)$ and people who inject drugs

(c) The Author(s). 2019 Open Access This article is distributed under the terms of the Creative Commons Attribution 4.0 International License (http://creativecommons.org/licenses/by/4.0/), which permits unrestricted use, distribution, and 
$(13.5 \%)[1,2]$. Among the injection drug users, the majority of whom were men [7], HIV prevalence ranged from 16 to $44 \%$, and three-quarters of those with HIV were infected through injection drug use [8-10]. Behavioural surveys have revealed the risks of onward HIV transmission due to $80 \%$ of the injection drug users being sexually active and $58 \%$ having multiple sex partners $[2,8,11]$. Approximately $40 \%$ of the injection drug users were also involved with sex workers or had sexual contact with other men, which meant a higher risk of contracting and transmitting HIV [3]. As such, people who inject drugs have the potential to act as a bridging population for the HIV epidemic, from the mainly injecting route to heterosexual transmission.

Meta-analyses of condom effectiveness in preventing HIV transmission revealed that consistent condom use between discordant couples has resulted in an overall $80 \%$ reduction in transmission risk [12], yet reported condom use among high-risk individuals remains low in many parts of the world [13]. Inconsistent condom use has been noted in previous studies among partners of injection drug users in the USA [14], India $[15,16]$ and Vietnam [5], where the rate of condom use in the studied populations ranged from 13 to $35 \%$.

While previous studies from various locations in Malaysia reported a low prevalence of condom use among men who injected drugs during their last sexual intercourse (only 14 to $28 \%$ ), limited local data are available to show the prevalence of condom use with their wives and steady partners $[2,8,11]$. This paper reports the prevalence of consistent condom use and the factors associated with this practice among the wives and sexual partners of men who inject drugs in Klang Valley, one of the regions in Malaysia severely affected by HIV through the sharing of injecting paraphernalia amongst intravenous drug users [2].

\section{Materials and methods Study location}

The survey was conducted in Klang Valley, Malaysia, which includes the Federal Territory of Kuala Lumpur and four surrounding districts in the neighbouring state of Selangor (Petaling, Selayang, Hulu Langat and Sepang). These areas were selected for their mixture of urban and sub-urban settings. This is a highly populated area, owing to an active economy and industrial activities, and it is home to approximately $10 \%$ (2.74 million out of 28.3 million) of the Malaysian population [17].

\section{Participant selection criteria and recruitment}

The eligible participants were women aged 18 years and above who were in a stable sexual relationship with a man who injected drugs (MWID) for at least six months. To ensure that the men were active injection drug users, recruitment was assisted by several non-governmental organizations outreach workers who were familiar with the population of drug users in the surveyed area. Sample size estimation was undertaken using the STATA Data Analysis and Statistical Software, version 13 [18], to detect a difference of $5 \%$ in the prevalence of condom use for each independent variable with $80 \%$ power when a type I error rate of $5 \%$ was assumed [4, 8, 19], giving an estimated sample size of 220 .

Given the difficulties in locating this "hard-to-reach" population, respondent-driven sampling (RDS) was undertaken. In RDS, a "seed" amongst the target population of interest is chosen, who will then begin recruiting his/her colleagues through a specially designed coupon with a tracking system. There is a quota for recruitment that helps to reduce oversampling among subjects with larger personal networks and produces a more heterogeneous group [20]. In this study, twelve men who injected drugs (MWIDs) who were married or had a regular sexual partner were initially identified in each location and recruited as the seed. The men were asked to invite their wife/regular sexual partner to the survey. Then, each MWID was provided with three recruitment coupons to pass to their friends who were active injection drug users and married or with a regular sexual partner. The newly recruited men were asked to invite their wife/regular sexual partner to participate in this study. All MWIDs who came with their wife/regular sexual partner to participate were given the opportunity to be a recruiter. During the data collection, the women were provided with a respondent information sheet and were ensured that their participation was voluntary and that they could choose not to participate at any time.

For the successful recruitment of female respondents, regardless of whether or not the women agreed to participate, the MWIDs received a cash amount of $10 \mathrm{Ma}-$ laysian ringgit (RM10), which is approximately 2.4 US dollars. This is to prevent the possibility of coercion and to ensure that the women are willing to participate on their own accord. An additional RM10 was given as a secondary incentive to the MWIDs for each successful recruit to compensate them for their time and effort in the recruitment process. The women who participated received RM20 for their participation in the survey. Educational materials on HIV prevention were supplied to the couples, including information where testing and, if needed, treatment could be obtained. The value of the incentive given in this study is considered acceptable and falls short of being coercive.

The recruitment chain continued for six months with a maximum chain length of six, resulting in the collection of 332 names and contact numbers of eligible women. Out of 332 eligible women, only 282 were contactable. Of these women, 50 refused to participate, and two women did not come despite agreeing to do so. Nine questionnaires were incomplete and missing several important 
data, resulting in 221 responses being analysed. The response rate for this study was $78.4 \%$.

\section{Study instrument}

A self-administered questionnaire was used in the survey. It was developed based on the theory of gender and power framework, which included physical exposure and behavioural risk factors, social norms and culture and socioeconomic risk factors [21, 22]. Physical exposure and behavioural risk factors were conceptualized into partner's HIV status, the use of injectable drugs among the participants and their involvement in sex work. Social norms and culture were conceptualized into marital status and sexual decision making, whereas socio-economic risk factors were conceptualized into education attainment, employment status and income. The questionnaire was developed in English and translated into Malaysian language by the primary researcher. To ensure consistency, the questionnaire was back-translated into English by a professional translator. Both the English and Malaysian versions of the questionnaires were pre-tested for face validity prior to the survey. Content validity was ensured by a panel of experts, including two public health physicians and one infectious diseases physician. The questionnaire included questions on condom use, socio-demographic characteristics, HIV status and HIV risk-related behaviour.

\section{Definition of variables}

\section{Consistent condom use}

Participants were asked how often their partners had used condoms when they had had sexual contact, which included vaginal or anal sex during the past six months. The options given were "never", "occasionally", "about half the time", "almost always" and "always". Due to the importance of consistent condom use for preventing sexually transmitted infections, including HIV, the responses were later dichotomised into "consistent condom users" and "nonconsistent condom users". "Consistent condom users" included those who reported "almost always" and "always" using condoms, while "non-consistent condom users" included those who had never used a condom or only used condoms "occasionally" or "about half the time" [23].

\section{Socio-demographic characteristics}

A range of socio-demographic characteristics were included in the survey, such as age, ethnicity, religion, study location, relationship status, employment status and education level. The study locations were divided into urban (Federal Territory of Kuala Lumpur, Petaling and Selayang districts) and sub-urban (Hulu Langat and Sepang districts).

\section{HIV status}

This is based on the self-reported HIV status of the participants and their partners. It was not validated with any biomedical testing or clinic record due to the anonymity of the questionnaire.

\section{HIV risk-related behaviour}

Participants were asked whether they had been involved in injection drug use or whether they had had multiple sex partners over the past 12 months. Those who had multiple sex partners were asked whether they had received any token in exchange for sex. Participants who answered "yes" were categorized as being involved in sex work.

\section{Data collection process}

During the data collection, participants who consented to participate in the study were requested to complete the survey form after a brief introduction by a trained research assistant. While completing the questionnaire, the participants were free to ask the research assistance for clarification if there was any question or terminology that they did not understand. Once the questionnaire had been completed, it was given to the research assistant in a sealed envelope to ensure confidentiality.

\section{Data analysis}

Data analysis was conducted using STATA Data Analysis and Statistical Software, version 13 [18]. Once the data had been cleaned, descriptive statistical analyses were undertaken to describe the study variables. Further analyses to identify the predictors of consistent condom use were performed, starting with simple logistic regression. This was followed by an adjusted analysis using multivariate logistic regression, where confounding effects of multiple variables towards the outcome measures were suspected. The level of statistical significance ( $p$-value) was set at 0.05 .

\section{Results}

\section{General characteristics of participants}

The participants' socio-demographic characteristics, reported HIV status and HIV-related risk behaviour are shown in Table 1.

The majority (69.2\%) of the participants were married to their current partner, and $76.9 \%$ were Muslim, with an almost equal distribution of participants in urban and sub-urban locations. With respect to education, nearly all (90.5\%) participants completed at least primary school. Seventy percent were working, either full or part time. Among the women surveyed, 20 (9.1\%) had used injectable drugs in the last 12 months, while $32(14.5 \%)$ had more than one sex partner in the last 12 months. Of these 32 women, 24 (66.7\%) reported receiving money, drugs or favours in exchange for sex and were categorized as being involved in sex work. Overall, $6.3 \%$ of the survey participants reported being HIV positive, while $7.7 \%$ reported 
Table 1 Participants' socio-demography, HIV status and HIV-risk related behaviours $(N=221)$

\begin{tabular}{|c|c|c|}
\hline Participants' characteristics & $n$ & $\%$ \\
\hline \multicolumn{3}{|l|}{ Marital status } \\
\hline Married to their current partner & 153 & 69.2 \\
\hline Not married to their current partner & 68 & 30.8 \\
\hline \multicolumn{3}{|l|}{ Religion } \\
\hline Islam & 170 & 76.9 \\
\hline Christianity & 7 & 3.2 \\
\hline Buddhism & 12 & 5.4 \\
\hline Hinduism & 32 & 14.5 \\
\hline \multicolumn{3}{|l|}{ Study Location } \\
\hline Urban & 114 & 51.6 \\
\hline Sub-urban & 107 & 48.4 \\
\hline \multicolumn{3}{|l|}{ Age group* } \\
\hline Youth ( $\leq 25$ years) & 13 & 6.1 \\
\hline Young adults ( $26-35$ years) & 65 & 30.2 \\
\hline Middle-aged adults (36-50 years) & 109 & 50.7 \\
\hline Older adults ( $\geq 51$ years) & 28 & 13.0 \\
\hline \multicolumn{3}{|l|}{ Highest education attainment } \\
\hline Never attended school or did not finish primary education & 21 & 9.5 \\
\hline Completed primary education & 65 & 29.4 \\
\hline Completed secondary education & 122 & 55.2 \\
\hline Completed tertiary education & 13 & 5.9 \\
\hline \multicolumn{3}{|l|}{ Employment status } \\
\hline Not working & 66 & 29.9 \\
\hline Working part time & 58 & 26.2 \\
\hline Working full time & 97 & 43.9 \\
\hline \multicolumn{3}{|l|}{ History of drug use in the last 12 months } \\
\hline Used injectable drugs & 20 & 9.1 \\
\hline Used non-injectable drugs & 67 & 30.3 \\
\hline Never used any drugs & 134 & 60.6 \\
\hline \multicolumn{3}{|l|}{ Had more than one sex partner } \\
\hline Yes & 32 & 14.5 \\
\hline No & 189 & 85.5 \\
\hline \multicolumn{3}{|l|}{ Involved in sex work } \\
\hline Yes & 24 & 10.9 \\
\hline No & 197 & 89.1 \\
\hline \multicolumn{3}{|l|}{ Participants' HIV status } \\
\hline Positive & 14 & 6.3 \\
\hline Negative & 148 & 67.0 \\
\hline Unknown & 59 & 26.7 \\
\hline \multicolumn{3}{|l|}{ Partners' HIV status } \\
\hline Positive & 17 & 7.7 \\
\hline Negative & 103 & 46.6 \\
\hline Unknown & 101 & 45.7 \\
\hline
\end{tabular}

Table 1 Participants' socio-demography, HIV status and HIV-risk related behaviours $(N=221)$ (Continued)

\begin{tabular}{lcc}
\hline Participants' characteristics & $\mathrm{n}$ & $\%$ \\
\hline HIV concordance & 5 & 2.3 \\
Both HIV positive & 9 & 4.1 \\
Sero-discordant (woman +ve, partner -ve or unknown) & 12 & 5.4 \\
Sero-discordant (woman -ve or unknown, partner +ve) & 195 & 88.2 \\
Both HIV negative or unknown & &
\end{tabular}

having partners who were HIV positive; $26.7 \%$ did not know their HIV status, and $45.7 \%$ had no information on their partner's HIV status. One in five women who injected drugs was HIV positive, and $29.2 \%$ of sex workers were HIV positive.

In terms of socio-economic characteristics, $70.1 \%$ of the participants were working either full time or part time. Twenty-seven participants did not answer the question on household income. Among the 194 participants who responded, their monthly income ranged from RM80 to RM5,000, with a mean (SD) of RM1,460 (RM963) and a median of RM1,200. A total of $63.4 \%$ of participants had a household income lower than RM1, 500 per month, which marked the poverty line for an average household of four people in Malaysia [24]. Women were the main earner in $38.9 \%$ of households, while another $35.8 \%$ shared this responsibility with their male partner.

\section{Prevalence of consistent condom use}

The pattern of condom use among the participants is shown in Table 2. The prevalence of consistent condom use in the past 12 months was 19.5\% (95\% CI: $14.5-$ $25.3 \%)$. Slightly more than half $(52.5 \%$; $95 \%$ CI: $45.7-$ $59.2 \%$ ) had never used condoms with their partner in their entire relationship. The prevalence of condom use among participants who were not married to their current partner was $38.2 \%$, compared to only $11.1 \%$ among participants who were married. Sero-discordant couples reported only $28.6 \%$ prevalence of consistent condom use. Additional information describing the reason for condom use, decision making and access to condoms is shown in Table 3.

\section{Predictors of consistent condom use}

Further analyses were conducted to identify factors predicting consistent condom use. The findings are shown in Table 4. Variables that showed a $P$-value of less than 0.05 in the simple logistic regression were further analysed using multiple logistic regression. After adjusting for study location, participants' HIV status and involvement in sex work, the odds of consistent condom use among unmarried women was approximately five times 
Table 2 Condom use among participants $(N=221)$

\begin{tabular}{lll}
\hline Condom use & $n$ & Percentage (\%) \\
\hline Have you ever used a condom? & 105 & 47.5 \\
Yes & 116 & 52.5 \\
No & & \\
Used condoms at last sex? & 64 & 28.9 \\
Yes & 41 & 18.6 \\
No & 116 & 52.5 \\
Not applicable (never used condom) & & \\
Frequency of condom use & 28 & 12.7 \\
Always (a) & 15 & 6.8 \\
Almost always (b) & 30 & 13.6 \\
About half the time (c) & 32 & 14.5 \\
Occasionally (d) & 116 & 52.5 \\
Never used a condom (e) & & \\
Consistent condom user & 43 & 19.5 \\
Yes (a + b) & 178 & 80.5 \\
No (c+ d + e) &
\end{tabular}

higher than that among women who were married (AOR = 4.95, 95\% CI: 2.45, 9.99). Women living in urban areas $(\mathrm{AOR}=2.97,95 \% \mathrm{CI}: 1.30,6.78)$, HIV-positive women $(\mathrm{AOR}=3.45,95 \% \mathrm{CI}: 1.13,10.5)$ and women who were involved in sex work $(\mathrm{AOR}=3.55,95 \% \mathrm{CI}$ : $1.45,8.67)$ had

Table 3 Additional information on condom use among participants who had ever used a condom $(N=105)$

\begin{tabular}{lcl}
\hline Additional information on condom use & $n$ & Percentage (\%) \\
\hline Reason for using condoms & 23 & 21.9 \\
To avoid pregnancy & 63 & 60.0 \\
To avoid STIs including HIV & 16 & 15.2 \\
Both of the above reasons & 3 & 2.9 \\
Other reasons & & \\
Who decides to use condoms? & 58 & 55.2 \\
The participant & 17 & 16.2 \\
Her partner & 30 & 28.6 \\
Shared decision by both of them & & \\
Who usually provides condoms?* & 74 & 71.2 \\
Only the participant & 18 & 17.3 \\
Only her partner & 12 & 11.5 \\
Both of them & 19 & 18.1 \\
Where do they normally get their supply of condoms? & \\
Government clinic & 52 & 49.5 \\
NGOs & 32 & 30.5 \\
Pharmacy & 2 & 1.9 \\
Convenience shop & & \\
\hline
\end{tabular}

*One participant did not answer the question higher odds of consistent condom use than did their respective reference groups.

\section{Discussion}

A key finding of this study is the high prevalence of unprotected sex among the participating women, whereby only one in five women had used condoms regularly with their partners during the 12 months prior to the study. The findings of this study resonate with previous research findings on condom use among MWIDs in Malaysia, which ranged from 14 to $22 \%$ in studies conducted in Kuala Lumpur and five other cities in Peninsular Malaysia [2, 8, 9]. However, data from these studies included condom use for all sexual contacts of MWIDs, regardless of whether the contact occurred with their long-term steady partners or with casual partners. Therefore, the results of the present study provide a more specific prevalence of consistent condom use within the intimate relationships of MWIDs and their long-term partners. This is important to distinguish because the issues that affect condom use and intervention plans for promoting safer sexual practices varied according to the type of relationship [3, 25]. This finding was elaborated upon by Diaz-Loving and Villagran-Vazquez (1999) in their work on the determinants of behavioural changes in the context of heterosexual HIV prevention in Mexico [26]. The researchers construed that subjective norms and the motivation for complying with reference groups appeared to be important determinants of condom use among women with regular partners.

In this study, a significantly lower proportion of condom users were married women and those living in rural areas, which could be due to the stronger effect of sociocultural factors and gender norms on these groups [27]. As an example, the norms of an ideal family life with both parents available to raise their children together led many women to remain married as they tried to fit into the expected role of a wife and mother. Being married also meant that the women were fully committed to the relationship and bound to the expected roles of a wife. In contrast, these expectations were not present among the unmarried couples, as the nature of their relationship is non-traditional in Malaysian culture. This is consistent with the finding of more consistent condom use among the unmarried women. In addition to their greater ability to make sexual decisions, unmarried women were not restricted by socio-cultural expectations in a marriage and therefore faced fewer barriers to sexual communication.

Condoms were also not popular among the youth, as none of the women aged 25 years and younger reported high condom use. The theory of gender and power suggests that power imbalances in a relationship can affect women's ability to negotiate for safer sexual practices [28]. Previous research has proposed that Malaysian women 
Table 4 Factors associated with consistent condom use ( $N=221)$

\begin{tabular}{|c|c|c|c|c|c|c|}
\hline \multirow{3}{*}{$\begin{array}{l}\text { Socio-demographic characteristics/HIV } \\
\text { status/HIV risk behaviour }\end{array}$} & \multicolumn{4}{|c|}{ Consistent condom use } & \multicolumn{2}{|c|}{ Multiple logistic regression } \\
\hline & \multicolumn{2}{|c|}{ Yes $(n=43)$} & \multicolumn{2}{|c|}{ No $(n=178)$} & \multirow[b]{2}{*}{$P$-value } & \multirow[b]{2}{*}{ Adjusted odds ratio ${ }^{a}(95 \% \mathrm{Cl})$} \\
\hline & $n$ & $\%$ & $n$ & $\%$ & & \\
\hline \multicolumn{7}{|l|}{ Marital status } \\
\hline Married to the current partner & 17 & 11.1 & 136 & 88.9 & \multirow[t]{2}{*}{$<0.001^{*}$} & Ref \\
\hline Not married to the current partner & 26 & 38.2 & 42 & 61.8 & & $4.95(2.45,9.99)$ \\
\hline \multicolumn{7}{|l|}{ Religion } \\
\hline Muslim & 29 & 17.1 & 141 & 82.9 & \multirow[t]{2}{*}{0.10} & \\
\hline Non-Muslim & 14 & 27.5 & 37 & 72.5 & & \\
\hline \multicolumn{7}{|l|}{ Study Location } \\
\hline Urban & 34 & 42.5 & 80 & 57.5 & \multirow[t]{2}{*}{$0.007^{*}$} & $2.97(1.30,6.78)$ \\
\hline Sub-urban & 9 & 9.2 & 98 & 90.8 & & Ref \\
\hline \multicolumn{7}{|l|}{ Age group } \\
\hline Youth ( $\leq 25$ years) & 0 & 0 & 13 & 100.0 & \multirow[t]{4}{*}{0.34} & \\
\hline Young adults ( $26-35$ years) & 12 & 18.5 & 53 & 81.5 & & \\
\hline Middle-aged adults ( $36-50$ years) & 22 & 20.2 & 87 & 79.8 & & \\
\hline Older adults ( $\geq 51$ years) & 6 & 21.4 & 22 & 78.6 & & \\
\hline \multicolumn{7}{|l|}{ Highest education attainment } \\
\hline Primary education or less & 21 & 24.4 & 65 & 75.6 & \multirow[t]{2}{*}{0.14} & \\
\hline Completed at least secondary education & 22 & 16.3 & 113 & 83.7 & & \\
\hline \multicolumn{7}{|l|}{ Employment status } \\
\hline Working & 32 & 20.6 & 123 & 79.4 & \multirow[t]{2}{*}{0.49} & \\
\hline Not working & 11 & 16.7 & 55 & 83.3 & & \\
\hline \multicolumn{7}{|l|}{ Participants' HIV status } \\
\hline Positive & 6 & 42.9 & 8 & 57.1 & \multirow[t]{2}{*}{$0.04^{*}$} & $3.45(1.13,10.5)$ \\
\hline Negative or unknown & 37 & 17.9 & 170 & 82.1 & & Ref \\
\hline \multicolumn{7}{|l|}{ Partners' HIV status } \\
\hline Positive & 6 & 35.3 & 11 & 64.7 & \multirow[t]{2}{*}{0.11} & \\
\hline Negative or unknown & 37 & 18.1 & 167 & 81.9 & & \\
\hline \multicolumn{7}{|l|}{ Used injectable drugs } \\
\hline Yes & 3 & 15.0 & 17 & 85.0 & \multirow[t]{2}{*}{0.77} & \\
\hline No & 40 & 19.9 & 161 & 80.1 & & \\
\hline \multicolumn{7}{|l|}{ Involved in sex work } \\
\hline Yes & 10 & 41.7 & 14 & 58.3 & \multirow[t]{2}{*}{$0.004^{*}$} & $3.55(1.45,8.67)$ \\
\hline No & 33 & 16.8 & 164 & 83.2 & & Ref \\
\hline
\end{tabular}

* Significant at $P<0.05{ }^{a}$ Adjusted odds ratio from multiple logistic regression adjusting for marital status, study location, participants' HIV status, and involvement in sex work Ref $=$ reference group in logistic regression

prefer to discuss issues with their partners before making decisions related to their own sexual and reproductive health [29]. Additionally, their decision-making abilities were strongly influenced by socio-cultural norms that served to entrench gender role expectations and enhanced their inferior position within the relationship. This situation is reported to be common in the patriarchal society of Malaysia [11, 27]. The implications of the participants' compliance with gender norms reduced the autonomy they had over their own bodies.
The results revealed a high proportion of unprotected sex among sero-discordant couples, whereby only approximately one in four women reported consistent condom use despite being aware that their partners were HIV positive. It was also noted that nearly half of the women did not know of their partners' HIV status. This put the women whose partners had HIV at great risk of being infected. A study conducted among Indian women that examined the factors associated with unprotected sex revealed a similar finding [30]. In that study, concerns 
regarding a partner's trust were identified as important factors contributing to women's lack of condom use despite their knowledge of the HIV-positive status of their sexual partners.

Several limitations were identified with the performance of this study. The use of RDS led to non-probability sampling in the survey, which limited the generalizability of the survey results [31] and introduced selection bias into the sample [32]. Furthermore, this was the first time that RDS had been used to recruit the partners of MWIDs, although the technique had previously been reported as useful for recruitment within a community of men who injected drugs [33, 34]. Although RDS is believed to be the best way to obtain a representative sampling of a hidden population, it proved extremely difficult to sustain the referral chain to reach the women because the referrals mainly depended on the network of MWIDs. There were not enough waves of chain referrals in several locations, as the network of MWIDs tends to be very small and mobile. This is due to their injecting habits; they preferred to inject in smaller groups and in a secluded and secure place as a survival strategy against frequent police raids. The tight law enforcement by police has led people who inject drugs (PWIDs) to make only brief contact with each other, essentially for obtaining their drug supply. This has made it difficult for them to recruit their peers into this study. Another limitation is related to the nature of the data collection, which is self-reported and may introduce information bias. The cross-sectional design also restricted any interpretations of causal relationships in the study findings.

\section{Conclusion}

The results from this study have shown that women who are intimately involved with PWIDs are vulnerable to HIV. Unprotected sex was a common practice, with only one in five women using condoms regularly with their partners. The high prevalence of HIV among their partners and the low use of condoms within their relationships underscore the heightened risk faced by these women. The challenges of consistent condom use within a long-term relationship call for other preventive strategies of HIV prevention within this population. These strategies need to include strengthening the HIV screening of PWIDs and encouraging their disclosure of their HIV status to their partners, while simultaneously empowering women by providing alternative prevention methods that they are able to control.

\footnotetext{
Abbreviations

AOR: Adjusted odds ratio; HIV: Human immunodeficiency virus; MWID: Man who injects drugs; NGO: Non-government organizations; PWID: Person who injects drugs
}

\section{Acknowledgements}

The authors would like to acknowledge the Malaysian AIDS Council and the Ministry of Health, Malaysia, for their support of this study.

\section{Authors' contribution}

RAM, SL and ND conceived and designed the study. RAM performed the data collection and data analysis. Fl advised on the technical aspects of the study and access to drug-using communities. ND and Fl supervised the analysis of the data. RAM, SL and ND drafted the paper. All authors have read and approved the manuscript.

\section{Author's information \\ Not applicable \\ Funding \\ This study received funding from the Malaysian Health Promotion Board research grant (4-LPKM/04/061/06/11). The funding body had no role in the study, data collection, data analysis, data interpretation, or in writing of the manuscript.}

\section{Availability of data and materials}

The datasets used and analysed during the current study are available from the corresponding author on reasonable request.

\section{Ethics approval and consent to participate}

This study was approved by the Research Ethics Committee of the University of Otago, New Zealand (12/140) and the Medical Research Ethics Committee, Ministry of Health, Malaysia (NMRR-12-392-11047). All participants gave written informed consent to participate in the study.

\section{Consent for publication}

Not applicable

\section{Competing interests}

The authors declare that they have no competing interests.

\section{Author details}

${ }^{1}$ Department of Community Health Faculty of Medicine \& Health Sciences, Universiti Putra Malaysia, 43400 Serdang, Selangor, Malaysia. ${ }^{2}$ Department of Preventive \& Social Medicine, Dunedin School of Medicine, University of Otago, P.O. Box 56, Dunedin 9054, New Zealand. ${ }^{3}$ School of Health Sciences, University of Canterbury, Private Bag 4800, Christchurch 8140, New Zealand.

Received: 2 May 2019 Accepted: 28 October 2019

Published online: 07 November 2019

\section{References}

1. Ministry of Health Malaysia: Country Progress Report on HIV/AIDS. In. Putrajaya: Ministry of Health Malaysia; 2018.

2. Ministry of Health Malaysia: Global AIDS Response Progress Report. Reporting Period January 2015 to December 2015. In Edited by HIV/STI Section DCD Putrajaya; 2016

3. UNAIDS: HIV transmission in intimate partner relationships in Asia. In. Geneva; 2009.

4. Kumar MS, Virk HK, Chaudhuri A, Mittal A, Lewis G. A rapid situation and response assessment of the female regular sex partners of male drug users in South Asia: factors associated with condom use during the last sexual intercourse. Int J Drug Policy. 2008;19(2):148-58.

5. Hammett TM, Nghiem THV, Kling R, Binh KT, Oanh KTH. Female sexual partners of injection drug users in Vietnam: an at-risk population in urgent need of HIV prevention services. AIDS Care. 2010;22(12):1466-72.

6. Hawa R, Underhill A, Logie C, Loutfy M. Social contexts and HIV vulnerabilities among south Asian women in the greater Toronto area: examining social norms. Health care for women international. 2018;39(2):129-53.

7. National Anti-Drugs Agency Malaysia: Drugs Statistics by Gender. In: 20142018. Kuala Lumpur; 2019.

8. Malaysian AIDS Council: The Integrated Bio-Behavioral Surveillance (IBBS) Survey 2009 Malaysia: preliminary findings. In Kuala Lumpur; 2009.

9. Vicknasingam B, Narayanan S, Navaratnam V. The relative risk among IDUs not in treatment in Malaysia. AIDS Care. 2009;21 (8):984-91.

10. Bazazi AR, Crawford F, Zelenev A, Heimer R, Kamarulzaman A, Altice FL. HIV prevalence among people who inject drugs in greater Kuala Lumpur recruited using respondent-driven sampling. AIDS Behav. 2015;19(12):2347-57.

11. Ministry of Health Malaysia, UNICEF: Women and girls confronting HIV and AIDS in Malaysia. In. Kuala Lumpur; 2008. 
12. Weller S, Davis-Beaty K: Condom effectiveness in reducing heterosexual HIV transmission (Review). In: Cochrane Database of Systematic Reviews 2002. Edited by Collaboration TC; 2007.

13. Larney S, Peacock A, Leung J, Colledge S, Hickman M, Vickerman P, Grebely J, Dumchev KV, Griffiths P, Hines L. Global, regional, and country-level coverage of interventions to prevent and manage HIV and hepatitis $C$ among people who inject drugs: a systematic review. Lancet Glob Health. 2017;5(12):e1208-20.

14. Iguchi M, Bux D, Kushner H, Lidz V. Correlates of HIV risk among female sex partners of injecting drug users in a high-seroprevalence area. Evaluation and Programme Planning. 2001;24:175-85.

15. Panda S, Suresh Kumar M, Saravanamurthy P, Mahalingam P, Vijaylakshmi A, Balakrishnan P: Sexually transmitted infections and sexual practices in injection drug users and their regular sex partners in Chennai, India Sexually Transmitted Diseases 2007, 34(4):250-253.

16. Solomon S, Srikrishnan A, Celentano D, Johnson S, Vasudevan C, Murugavel K, Anand S, Kumar MS, Solomon S, Mehta S: The intersection between sex and drugs: a cross-sectional study among the spouses of injection drug users in Chennai, India BMC Public Health 2011, 11(1):39.

17. Department of Statistics Malaysia: Population distribution and basic demographic characteristics 2010. In: Population and Housing Census of Malaysia. Putrajaya; 2010

18. Statacorp: STATA Data Analysis and Statistical Software, Version 13. In. Texas: StataCorp; 2013

19. Harvey SM. New kinds of data, new options for HIV prevention among women: a public health challenge. Health Educ Behav. 2000;27(5):566-9.

20. Heckathorn DD. Respondent-driven sampling: a new approach to the study of hidden populations. Soc Probl. 1997;44(2):174-99.

21. DePadilla L, Windle M, Wingood G, Cooper H, DiClemente R. Condom use among young women: modeling the theory of gender and power. Health Psychol. 2011;30(3):310.

22. Guan M, Coles VB, Samp JA, Sales JM, DiClemente RJ, Monahan JL. Incorporating communication into the theory of planned behavior to predict condom use among African American women. J Health Commun. 2016;21(9):1046-54.

23. Noar SM, Cole C, Carlyle K. Condom use measurement in 56 studies of sexual risk behavior: review and recommendations. Arch Sex Behav. 2006;35(3):327-45.

24. Government of Malaysia: Household Income Poverty Line. In. Edited by Economic Planning Unit PMsD. Putrajaya; 2007.

25. Sherman S, Latkin C. Intimate relationship characteristics associated with condom use among drug users and their sex partners: a multilevel analysis. Drug Alcohol Depend. 2001;64:97-104.

26. Diaz-Loving R, Villagran-Vazquez $\mathrm{G}$. The theory of reasoned action applied to condom use and request of condom use in Mexican government worker. Applied Psychology: An International Review. 1999:48(2):139-51.

27. Hirschman C. Gender, the status of women, and family structure in Malaysia. Malays J Econ Stud. 2017;53(1):33-50

28. Wingood G, DiClemente R. Application of the theory of gender and power to examine HIV-related exposures, risk factors, and effective interventions for women. Health Educ Behav. 2000;27(5):539-65.

29. Najafi F, Rahman HA, Juni MH. Barriers to modern contraceptive practices among selected married women in a public university in Malaysia. Global J Health Sci. 2011;3(2):50-5.

30. Ananth P, Koopman C. HIV/AIDS knowledge. Beliefs and behavior among women of childbearing age in India. AIDS Education \& Prevention. 2003; 15(6):529-46.

31. Magnani R, Sabin K, Saidel T, Heckathorn D. Review of sampling hard-toreach and hidden populations for HIV surveillance. AIDS. 2005;19:567-72.

32. Kirkwood B, Sterne J. Essential Medical Statistics. Oxford, UK: Blackwell Publishers; 2003

33. Robinson WT, Risser JM, McGoy S, Becker AB, Rehman H, Jefferson M, Griffin $\checkmark$, Wolverton M, Tortu S. Recruiting injection drug users: a three-site comparison of results and experiences with respondent-driven and targeted sampling procedures. J Urban Health. 2006;83(1):29-38.

34. Malekinejad M, Johnston LG, Kendall C, Kerr LRFS, Rifkin MR, Rutherford GW. Using respondent-driven sampling methodology for HIV biological and behavioral surveillance in international settings: a systematic review. AIDS Behav. 2008;12:105-30

\section{Publisher's Note}

Springer Nature remains neutral with regard to jurisdictional claims in published maps and institutional affiliations.

\section{Ready to submit your research? Choose BMC and benefit from:}

- fast, convenient online submission

- thorough peer review by experienced researchers in your field

- rapid publication on acceptance

- support for research data, including large and complex data types

- gold Open Access which fosters wider collaboration and increased citations

- maximum visibility for your research: over $100 \mathrm{M}$ website views per year

At BMC, research is always in progress.

Learn more biomedcentral.com/submissions 